\title{
PORTOS COMO ÂNCORA DE DESENVOLVIMENTO TERRITORIAL DAS PEQUENAS E MÉDIAS CIDADES PORTUÁRIAS COM CANAIS: PORTO E CIDADE DE AVEIRO.
}

\author{
Lídia Maria Moreira Matias \\ Faculdade de Ciências Sociais e Humanas - FCSH, Universidade Nova de Lisboa - UNL, Portugal \\ Diretor da investigação: Professor Doutor João Figueira de Sousa \\ lidia.matias.1@gmail.com
}

\begin{abstract}
RESUMO
O objetivo principal desta investigação é avaliar o papel dos portos como âncora de desenvolvimento territorial das pequenas e médias cidades europeias com canais aquáticos, enquanto elementos centrais de organização espacial e funcional urbana.

O caso de estudo "O Porto e a Cidade de Aveiro" é analisado nas diferentes escalas territoriais e temporais tendo por base uma análise de benchmarking que incidiu sobre as pequenas e médias cidades de Gent, Bruges, Mechelen, Veneza, Huelva e os respetivos portos circundantes, considerando a dimensão populacional entre 20.000 e 500.000 habitantes, segundo o relatório Europa 2000+ (CE,1995).

Para cumprir o objetivo principal, a investigação pretende estruturar uma matriz de critérios de análise como principal ferramenta de análise de dados quantitativos e qualitativos. Assim, a investigação passará por diversos métodos nomeadamente a compilação de material gráfico e bibliográfico, análise dos mesmos na escala local e regional e posteriormente a interpretação das realidades territoriais expressadas na matriz de critérios de análise e na cartografia.
\end{abstract}

Palavras chave: cidades portuárias, cidades médias, porto de Aveiro, cidade de Aveiro.

\begin{abstract}
The main purpose of this research is to assess the role of harbours as anchors for territory development of small and medium sized European cities with water canals, as central elements for spatial and functional urban organisation.

The study case "Harbour and City of Aveiro" is analysed on various territory and time scales based on a benchmarking analysis that having as examples of study of the small and medium sized cities of Gent, Bruges, Mechelen, Venice, Huelva and their respective surrounding harbours, considering a population ranging between 20.000 and 500.000 inhabitants, according to the report Europe 2000+ (CE, 1995).

So as to accomplish this purpose, the research intends to structure a matrix for analysis criteria as the main quantitative and qualitative analysis tool. Thus the research shall rely on various methods, namely a compilation of graphic and bibliographic material, and corresponding analysis on a local and regional scale and later interpretation of territorial realities expressed on the matrix of criteria analysis and cartography.
\end{abstract}

Key words: port cities, medium cities, harbour of Aveiro, Aveiro city. 


\section{INTRODUÇÃO}

Os portos e as cidades têm uma ligação histórica muito forte. Neste contexto, questiona-se se os portos ainda são impulsionadores do crescimento urbano e territorial.

Os portos estão na origem de muitas cidades pelo que muitas destas começaram como portos comerciais, sendo o porto interface natural entre a terra e o mar. No passado, os portos permitiram que pequenas cidades se tornassem cidades de maior dimensão pelo que estes, impulsionaram o desenvolvimento urbano e territorial fomentado pelo comércio.

$\mathrm{Na}$ análise de cartografia histórica de algumas cidades, são destacadas fortes interligações entre o porto e o desenvolvimento urbano e territorial, pelo que historiadores económicos como Fernand Braudel (1979), salientaram a importância das cidades portuárias na origem e no desenvolvimento da economia global do mercado capitalista.

Fernand Braudel (1979) afirmou que a centralidade das cidades marítimas na época pré-revolução Industrial esteve relacionada com a sua inserção nas rotas marítimas comerciais que a partir dos séculos XVII e XVIII adquiriram dimensão mundial.

Geógrafos como James Bird (1963), André Vigarié (1979) e Brian Hoyle (1989), descreveram a expansão das atividades portuárias como contributo para o desenvolvimento urbano e portuário. Desta forma, na perspetiva histórico-morfológica, o modelo Anyport elaborado por Bird (1963) pretendia identificar e analisar a natureza e a evolução histórica referente à funcionalidade portuária e urbana. A reflexão teórica de James Bird entendeu o espaço portuário como uma sucessão cronológica da evolução do desenvolvimento físico dos portos. O modelo Anyport, refere inicialmente o desenvolvimento da cidade portuária a partir de um porto com uma localização adjacente ao centro urbano. A escolha dessa localização original dependia das referências geográficas e das funções portuárias (Bird, 1963). Segundo Hoyle (1989), o porto tinha uma relação física e funcional com o tecido urbano sem fronteira entre as duas estruturas com uma simbiose urbana, económica e social.

Exemplo de desenvolvimento de cidade portuária na época pré-revolução industrial, pode-se enunciar o porto e a cidade de Aveiro (caso de estudo), dado que ao longo do século XVIII, o assoreamento da barra e a sua deslocação para sul, afastaram Aveiro do mar, tornando precárias as condições de navegação, o que contribuiu para a decadência do porto. Com o encerramento da barra, houve um forte êxodo demográfico para o interior da região causado pela quebra das atividades económicas. No século XIX no âmbito do Fontismo, a barra do porto de Aveiro foi inaugurada em 1808, pelo que foram impulsionadas de novo as trocas comerciais entre Aveiro e os restantes países da Europa e Norte de África, além do crescimento da pesca de bacalhau nos mares do Canadá e do Norte da Europa.

$\mathrm{Na}$ época da Revolução industrial, a expansão das atividades industriais contribuiu para o intercâmbio comercial e aumentaram a circulação de mercadorias em todas as escalas, nomeadamente no transporte marítimo. Durante o século XIX, o aumento da atividade comercial e a reestruturação do espaço portuário contribuíram para o crescimento da diversificação de funcionalidades urbanas. Assim, existiram descontinuidades espaciais criadas por barreiras arquitetónicas, nomeadamente as vias férreas que ligavam os diversos cais portuários à cidade e os grandes armazéns que interromperam a relação porto-cidade. Em resumo, a era da expansão portuária segundo Bird (1963) configurou uma dinâmica de afastamento do porto em relação à cidade. Nessa época, o porto de Aveiro criou as denominadas descontinuidades através da criação de armazéns, além da já existente distância física entre a cidade de Aveiro e o seu porto. O porto de Aveiro era um porto marítimo cuja ligação do mesmo à cidade e ao restante território era feita através da Ria de Aveiro pelos barcos moliceiros ${ }^{1} \mathrm{e}$ através da estrada municipal que ligava o porto à cidade de Aveiro.

Posteriormente, o porto e a cidade separaram-se fisicamente e economicamente (Seassaro,1999; Hayuth,1982; Hoyle,1989; Henry, 2006; Wang \& Olivier, 2003). A necessidade de espaço e as limitações físicas e operacionais, contribuíram para que surgisse uma mudança na escala de produção e do transporte, pelo que as estruturas produtivas e portuárias tiveram de ser relocalizadas fora dos centros urbanos. Assim, surgiram navios especializados em carga específica e com maior dimensão, nomeadamente no transporte de granéis sólidos e líquidos, que contribuíram para a construção de unidades petroquímicas, químicas e siderúrgicas em zonas industriais e portuárias, nomeadamente os casos de Antuérpia e Roterdão. Segundo Hoyle (1989), surgiu na época uma relação muito forte entre o porto e a cidade industrial moderna, onde o porto tinha a função de transbordo de mercadorias destinadas às zonas industriais que abasteciam o

1 Barco moliceiro são barcos de borda baixa para facilitar o carregamento do moliço. Os moliceiros têm uma proa e uma ré muito elegantes. O comprimento total destes barcos atinge os 15 metros e a largura de boca tem aproximadamente 2,50 metros. Navega com pouca altura de água. O castelo da proa é coberto. Como meios de propulsão, usavam uma vela, a vara e a sirga. A sirga era um cabo que se utilizava na passagem dos canais mais estreitos ou junto às margens, quando navegava contra a corrente ou contra o vento. 
hinterland do porto (Cocco, Silva,1999). Assim, o transporte terrestre contribuía para a consolidação da distância entre a cidade e o porto (Vigarié, 1979; Lavaud-Letilleul, 2007; Monié, 2011).

$\mathrm{Na}$ época pós-industrial, o porto de Aveiro funcionava como transbordo de mercadorias que eram transportadas para todo o distrito de Aveiro e a cidade continuava distante do Porto por motivos físicos. Em 1967 foi concluída a obra do porto comercial de Aveiro, pelo que nesta data surgiram grandes armazéns onde armazenavam as mercadorias que eram transportadas para o hinterland que se limitava na época ao distrito de Aveiro.

A partir da década de 1970, a reorganização do transporte marítimo e a atividade portuária contribuíram para uma "remodelação de frente de água" (Hoyle, 1989). Nas áreas portuárias abandonadas foram criados espaços verdes e recreativos, como foi o caso de Nova Orleães, Boston, Toronto e Montreal (Chaline, 1988:700).

Na década seguinte (1980), com o aumento do desemprego e a diminuição de receitas fiscais, as autoridades públicas intervieram nas áreas portuárias abandonadas, implantando áreas comercias e equipamentos de lazer, com a intenção da criação do modelo de cidade pós-industrial (Hoyle,1989; Harvey, 1989; Chaline et al., 1994).

Nas décadas de 1980 e 1990, destacaram-se vários autores, nomeadamente Jordi Borja e Manuel Castells (1998) que teorizaram a metrópole internacional administrada como uma empresa reestruturada segundo princípios de competitividade territorial, no âmbito de captação de investimento produtivo, de turismo e de grandes eventos (Castells, 1999; Borja \& Castells, 1998).

No contexto da dinâmica porto-cidade, surgiram as operações de captação de fluxo de mercadorias, de investimento, de pessoas e de eventos que constituíram um indicador de maior produtividade dos terminais portuários e da cidade pós-industrial. Assim, surgiu a reaproximação entre a cidade e os antigos cais portuários através da integração de novos usos.

A questão central da tese é saber como os portos podem continuar a contribuir para o crescimento económico e social de uma cidade e região. A relação porto-cidade evoluiu ao longo do tempo e vários autores analisaram as fases de desenvolvimento do porto e da relação dinâmica de interação porto-cidade. Desta forma, foram analisados os impactos dos portos sobre as cidades, no âmbito económico-social e tecnológico, ambiental, tráfego marítimo e terrestre, segurança nos portos, criminalidade e impacto visual dos portos na área envolvente.

\section{PROBLEMÁTICA}

Nas ultimas décadas foram desenvolvidos vários estudos sobre a relação porto-cidade, onde existiram várias abordagens sobre a cidade portuária e a relação porto-cidade desenvolvidas por autores como Bird (1963) e Brian Hoyle (1989), Han Meyer (2011), Dirk Schubert (2011), Joan Busquets (2011), Enrico Musso e Hilda Ghiara (2011), Figueira de Sousa (2011) e outros investigadores. Assim, podemos distinguir dois pontos de abordagem no âmbito da temática porto-cidade, nomeadamente o primeiro dedica-se à influência da atividade portuária na cidade e o segundo sobre as transformações territoriais das cidades portuárias até ao período pós-industrial.

A primeira abordagem inclui várias investigações realizadas sobre as operações portuárias, que se direcionam sobre a economia portuária e urbana, sobre as tecnologias usadas na atividade portuária e ainda no impacto ambiental do porto no espaço envolvente. Destacam-se ainda os estudos sobre os impactos económicos das atividades portuárias na cidade e das análises comparativas sobre a dinâmica portuária e urbana, nomeadamente as análises estatísticas de indicadores e critérios usados para os estudos da relação portocidade. Estudos esses que ainda necessitam de desenvolvimento para atingir dados relevantes para as futuras investigações.

A segunda abordagem inclui investigações realizadas sobre a cidade onde o porto realiza o manuseamento de carga, mas cuja área urbana ficou abandonada devido ao porto ter sido desativado e deslocalizado para uma área urbana mais afastada da cidade. Assim, surgiram as transformações das frentes de água urbanas, nomeadamente no que se refere às transformações urbanísticas e funcionalidades urbanas. Foi um movimento que surgiu na década de 1960 nos EUA, denominado "waterfront".

Assim, existiram três momentos cronológicos que se consideraram importantes na evolução dos portos, nomeadamente o período pré-industrial, o industrial e o pós-industrial, cujos intervalos temporais associados às transformações estruturais da sociedade, eram referências nas transformações territoriais que resultaram da alteração da respetiva lógica produtiva. Após a análise das cidades portuárias selecionadas no âmbito da investigação do doutoramento, serão definidos diversos momentos temporais e características territoriais distintas nos três períodos histórico-morfológicos da evolução industrial.

Os portos destacam-se enquanto plataforma terrestre de apoio ao transporte marítimo e às funções portuárias, onde os impactos se foram expandindo no território e as cidades afastando-se para zonas mais 
distantes, por motivo das necessidades exigidas pela atividade portuária e pelo transporte marítimo. Surge a diversificação das funções portuárias e dos impactos portuários em zonas mais afastadas das cidades e da área portuária.

Empiricamente, a relação porto-cidade ocorre no caso de estudo porto e cidade de Aveiro e nas cinco pequenas e médias cidades portuárias europeias selecionadas com características morfológicas e demográficas semelhantes, em escalas territoriais diferentes e no mesmo período temporal.

Propõe-se investigar os impactos territoriais e funcionais à escala urbana e regional dos portos nas pequenas e médias cidades portuárias e nas regiões envolventes, dado já existirem diversos estudos sobre os impactos económicos dos portos nas grandes cidades, pelo que se pode optar pelo desenvolvimento de uma nova metodologia e testar a mesma.

Assim, são estudadas as diferentes tipologias de impactos do porto no território em diversas escalas temporais e territoriais diferentes, nas cidades portuárias europeias de pequena e média dimensão com canais aquáticos, onde o caso de estudo é o porto e a cidade de Aveiro. As cidades selecionadas têm a especificidade de terem canais na sua estrutura morfológica, o que pode ser importante para perceber a articulação entre o porto e o território envolvente, no que se refere às escalas, aos impactos, à intensidade e complexidade de atividades.

A presente investigação centra-se nas duas perspetivas de análise porto-pequena e média cidade e portoregião, tendo em consideração a especificidade das pequenas e médias cidades portuárias: "Portos nas Pequenas e Médias Cidades" e "Pequenas e Médias Cidades nos Portos" para posteriormente na análise de resultados, elaborar uma perspetiva global de análise "Portos e Pequenas e Médias Cidades", em seis pequenas e médias cidades portuárias europeias com canais aquáticos, sendo o caso de estudo o porto e a cidade de Aveiro.

A investigação estrutura-se sobre sete questões: socioeconómica, ambiental, tráfego, segurança e morfológica, em duas escalas distintas: territorial e cronológica. A escala territorial integra o estudo no âmbito do desenvolvimento urbano local, regional e nacional. A cronologia refere-se ao respetivo estudo a partir do século XIX até à atualidade.

Os problemas referenciados anteriormente, têm consequências sociais no âmbito do aumento ou diminuição de emprego dos cidadãos e êxodo populacional; ambientais no âmbito da degradação do solo, da água e da atmosfera, alterações climáticas que envolvem problemas no âmbito da subida do nível de água nas cidades provocando inundações das mesmas; acessibilidade no âmbito de ruído e sobrecarga das infraestruturas viárias; segurança no que se refere ao armazenamento e transporte de mercadorias que apresentam risco de explosão, explosivos na proximidade de centrais nucleares e químicas; criminalidade que integra o tráfico de droga e armas; urbanísticas no aspeto de alteração da estrutura do território em termos de densidade edificada e sobrecarga de infraestruturas públicas e regeneração das áreas portuárias devolutas.

Poderão caracterizar-se os impactos diretos, indiretos e induzidos dos portos, nomeadamente no caso de estudo de Aveiro, como porto na escala local, regional, nacional e internacional, dado no passado ter existido uma grande ligação económica, social e urbanística entre o porto e a cidade de Aveiro.

Os procedimentos adotados na aplicação da matriz de análise de critérios baseados em vários indicadores, têm a função de recolha de indicadores para elaboração de uma matriz para sistematização de dados comparativos entre cidades e aplicar na análise, onde se possa avaliar e compreender os indicadores.

O ensaio metodológico baseia-se em seis pequenas e médias cidades portuárias europeias com características morfológicas (portos e canais aquáticos) e demográficas (população inferior ou igual a 500.000 habitantes) similares, localizadas a norte, a sul e na parte ocidental da Europa, nomeadamente: a) porto de Antuérpia e cidade de Mechelen; b) porto e cidade de Gent; c) porto e cidade de Bruges; d) porto e cidade de Veneza; e) porto e cidade de Huelva; f) porto e cidade de Aveiro.

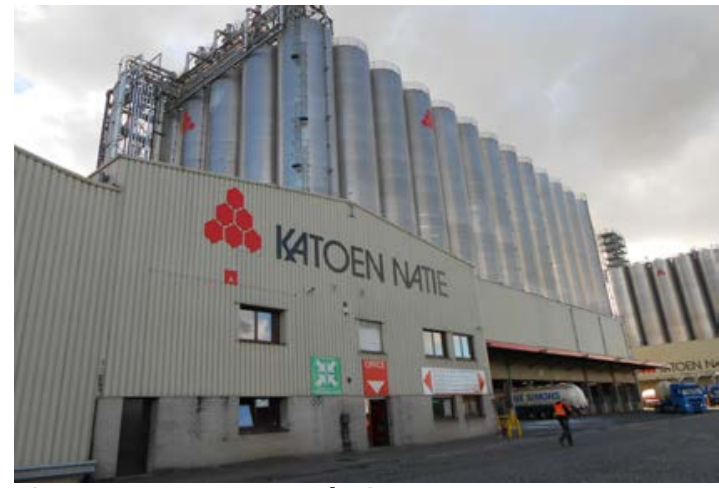

Figura 1: Porto de Antuérpia

(Matias, 2016)

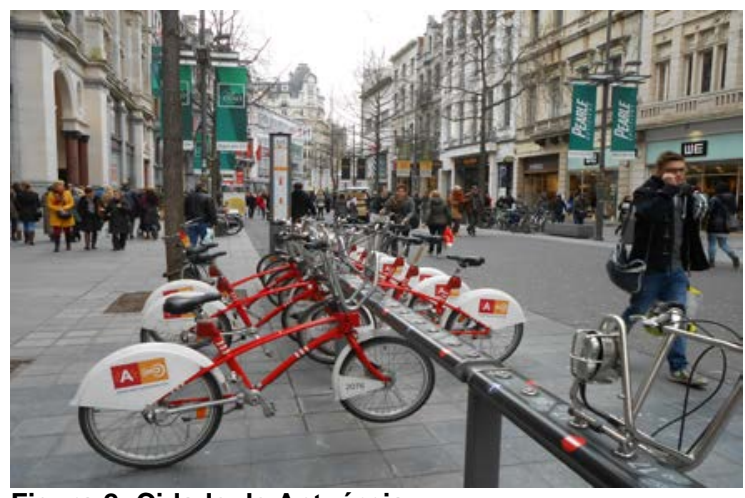

Figura 2: Cidade de Antuérpia (Matias, 2016) 


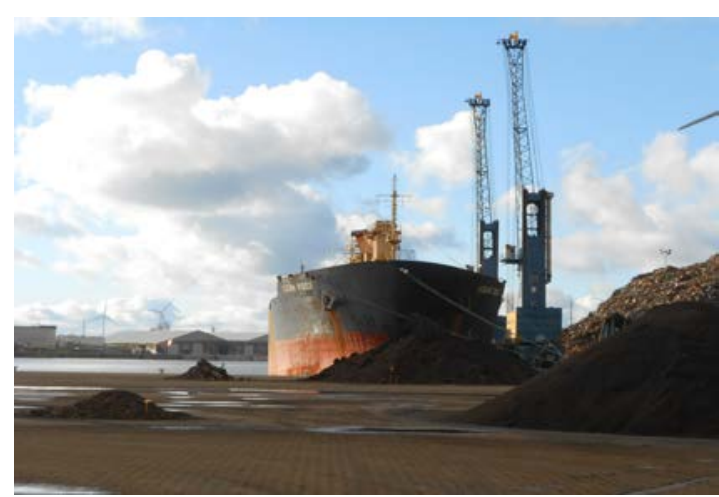

Figura 4: Cidade de Gent (Matias, 2016)

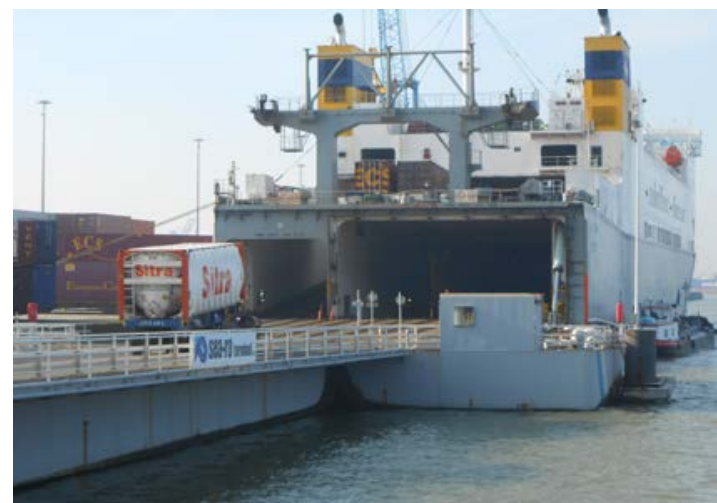

Figura 5: Porto de Zeebrugge (Matias, 2016)

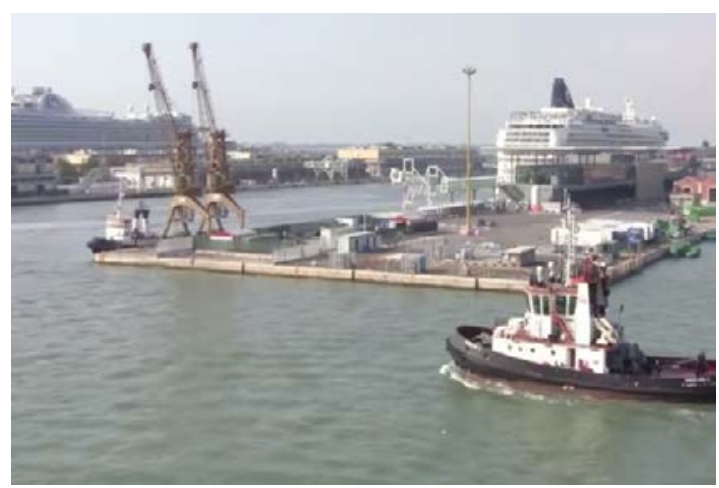

Figura 7: Porto de Veneza

(Matias, 2016)

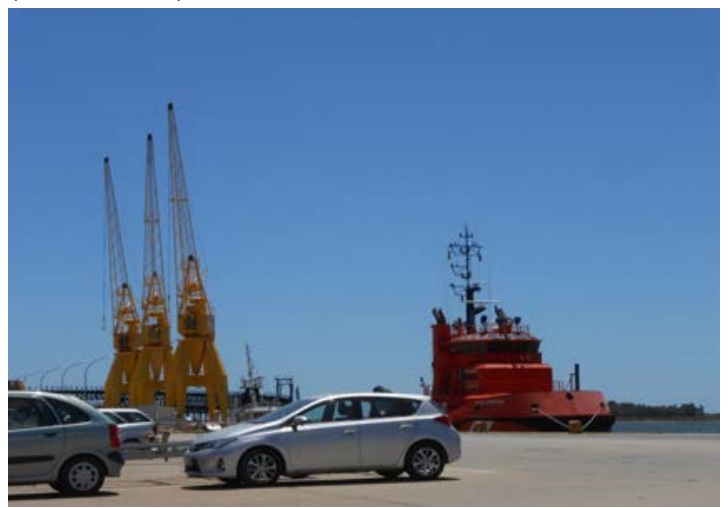

Figura 9: Porto de Huelva

(Matias, 2017)

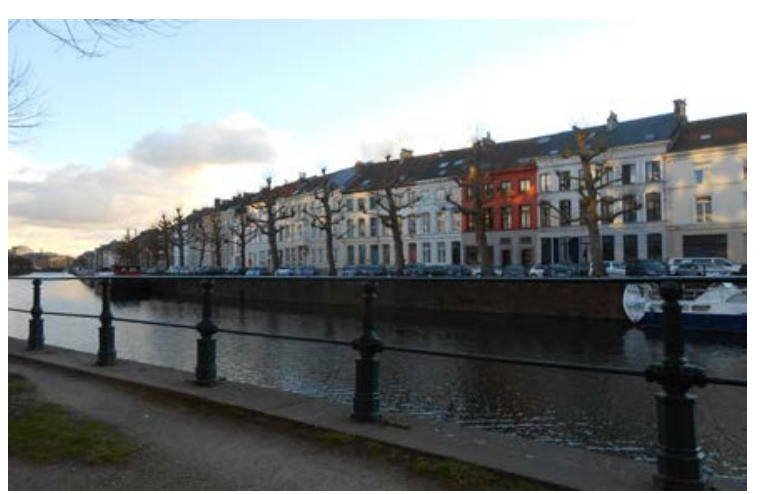

Figura 4: Cidade de Gent (Matias, 2016)

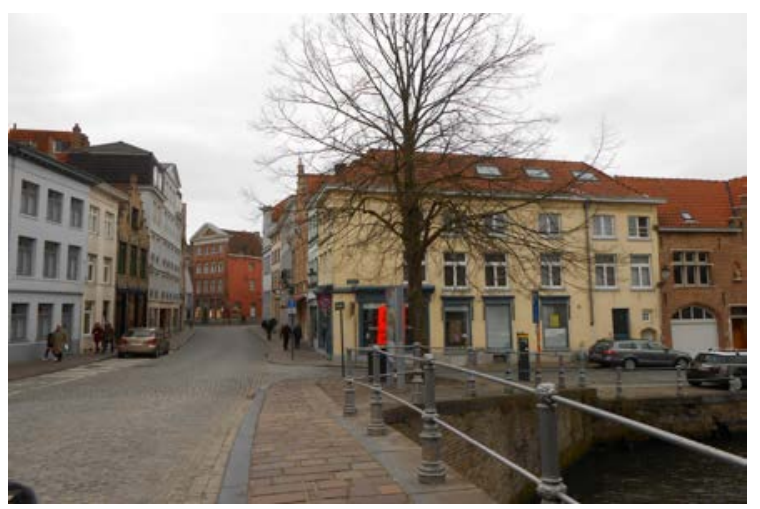

Figura 6: Cidade de Bruges

(Matias, 2016)

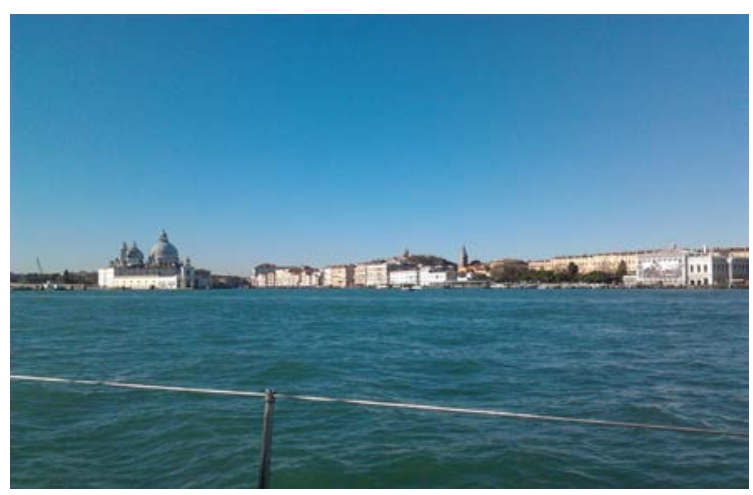

Figura 8: Cidade de Veneza

(Matias, 2016)

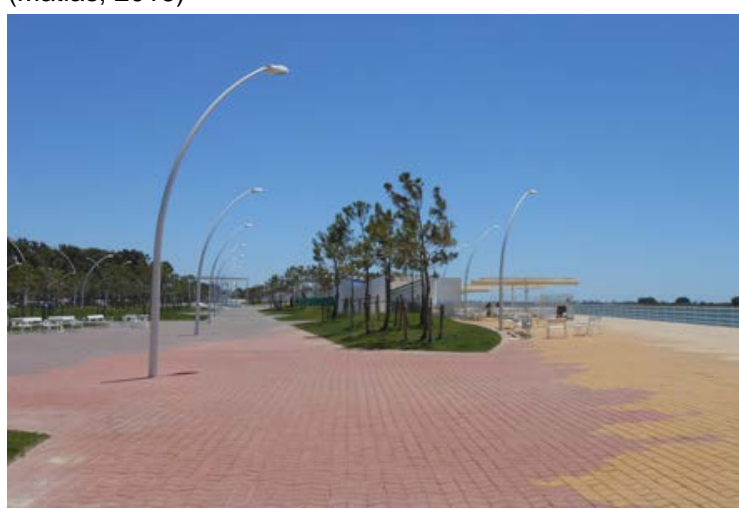

Figura 10: Cidade de Huelva

(Matias, 2017) 


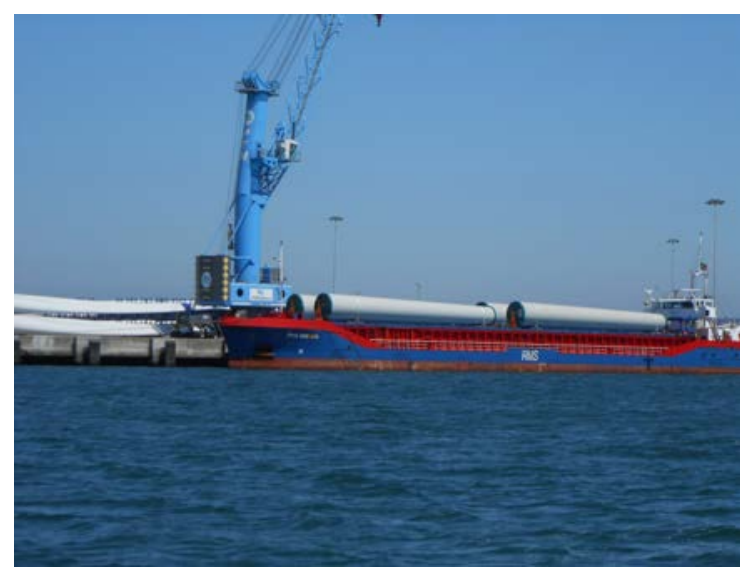

Figura11: Porto de Aveiro

(Matias, 2015)

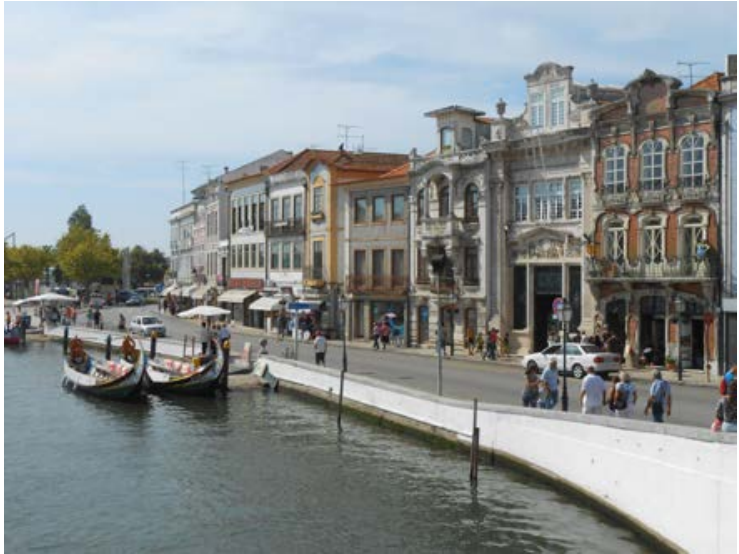

Figura 12: Cidade de Aveiro

(Matias, 2017)

No âmbito dos estudos da relação porto-cidade, destacam-se ainda em diversas universidades de cidades portuárias europeias, investigadores como Brian Hoyle em Southampton, Joan Busquets em Barcelona, Dirk Schubert em HafenCity Hamburgo e Han Meyer em Delft.

Bird (1963) e Hoyle (1989) fizeram várias investigações sobre as etapas sucessivas da separação portocidade. O interface porto-cidade é o espaço de transição das funções portuárias e urbanas, característico das intervenções mais recentes.

Joan Busquets (2011: 201-202), descreve inicialmente o porto como um todo e qualquer contacto com a água e função de intercâmbio se realizava no mesmo. Posteriormente, passou a existir o porto de água, onde se realizava a pesca e a chegada e saída de passageiros e mercadorias. Ou seja, para entendimento da lógica da transformação portuária é necessário programar um modelo sobre a evolução progressiva da especialização de funcionalidades que alteram gradualmente os requisitos funcionais e estratégicos dos portos. Assim, no decorrer de necessidades mais específicas, a evolução da atividade portuária decorre no sentido do surgimento inicial de atividades primárias (pesca e matérias primas), posteriormente, atividades secundárias (industria e logística), terciárias (equipamentos e serviços) e atualmente atividades quaternárias (atividades inovadoras e recreativas).

Dirk Schubert (2011: 185), contextualizou os fatores topográficos, a história portuária e urbana local, os cidadãos e as estruturas governamentais, como indicadores que oferecem um marco de referência para a identificação dos diferentes processos de desenvolvimento urbano e sociocultural. Desta forma, os portos estão a converter-se em mundos isolados, separados do contexto urbano, cercados pelas cidades, mas com uma estrutura interna de emprego, de operadores e de estruturas administrativas. Ainda que as antigas áreas portuárias próximas da cidade tenham sido reintegradas no tecido urbano, as novas infraestruturas portuárias são separadas da estrutura urbana e localizadas em áreas que dispõem de águas profundas e de extensas áreas de terreno.

No entanto, Han Meyer (2011:163) estuda a reorganização espacial dos portos e das relações entre portos, cidades e territórios que se fundamenta em quatro importantes acontecimentos: a) portos enquanto regionalização e diferenciação; b) cidades enquanto procura crescente de identidade local e autoorganização; c) alterações climáticas que provocam o aumento do nível do mar; d) alterações dos recursos energéticos. Neste âmbito, é possível desenvolver estratégias globais que combinem estes quatro elementos que permitam configurações espaciais sustentáveis. Em consequência da globalização e da crescente competição entre portos, as autoridades portuárias mundiais reconsideram a posição dos portos nas redes de transporte global. No entanto, a expansão é gradualmente mais difícil devido aos conflitos de interesses que se geram entre a área urbana e rural vizinha como também pela sobrecarga das redes de transportes viários e ferroviários que surgem quando as atividades portuárias se concentram numa área. Desta forma, surge a necessidade crescente de equipamento flexível nos portos, pelo que a introdução de plataformas flutuantes para contentores torna possível a redução do espaço portuário (Ligteringen, 2010).

Figueira de Sousa (2011:129) contextualiza a relação porto-cidade como um tema de investigação complexo devido à sua multiplicidade de interações estabelecidas no âmbito do sistema territorial que sintetizam o conjunto de dinâmicas dos vários elementos constituintes do tríptico portuário, nomeadamente portohinterland terrestre-foreland marítimo. O autor refere que não existe um planeamento interdisciplinar com a função de compreensão do respetivo tríptico, nas diferentes dimensões temporais e espaciais.

Os autores Enrico Musso e Hilda Ghiara (2011:87), definem a relação simbiótica entre transportes e território, como forma de compreensão da relação porto-cidade-território. Assim, destacam o transporte como influência no desenvolvimento económico e físico futuro da cidade e do território envolvente, enquanto o desenvolvimento da cidade e respetivo território influencia as decisões de disponibilidade dos transportes. 
Contextualizando os portos como eixo estruturante das atividades económicas conectadas funcionalmente com a atividade portuária, o porto tem um efeito polarizador.

Como complemento destes estudos, destacam-se ainda "Guide of good practices" realizado por AIVP em 2007 (Lemaire, 2007) onde se estudaram seis cidades portuárias e se avaliaram as boas práticas para a integração espacial, económica e social das mesmas como a ESPO em 2010, publicou o "Code of Practice on Societal Integration of Ports", onde foram analisadas catorze cidades portuárias (Verhoeven, 2010). Também existem diversas associações internacionais que se dedicam à investigação sobre cidades portuárias, nomeadamente WAVE (Waterfront Vitalization and Environment Research Foundation) que surgiu em 1987 em Tóquio, AIVP (Association Internationale Villes et Ports) que surgiu em 1988 em Le Havre, o Centro Internazionale Città d'Acqua criado em 1989 em Veneza, ESPO (European Sea Port Organization) fundada em 1993 em Bruxelas, RETE (Asociación para la Colaboracón entre Puertos y Ciudades) surgiu em 2001 em Veneza. Todas estas associações têm tido uma importante função na divulgação da problemática porto-cidade e são plataformas de intercâmbio de boas práticas e de centros de informação e formação no âmbito do desenvolvimento das cidades portuárias.

A investigação contribuirá para a valorização do conhecimento científico sobre os impactos dos portos nas pequenas e médias cidades portuárias, as suas problemáticas e as boas práticas, adicionando conhecimento científico à comunidade nacional e internacional.

Entre as diversas investigações, Charlier e Malézieux (1997) defenderam que as antigas áreas portuárias deveriam ser reconvertidas, passando por ter novas funcionalidades portuárias diferentes da regeneração urbana, que não têm qualquer conexão com a cidade portuária (Charlier \& Maléziuex, 1997: 107-114).

No entanto, Ducret (2011: 41-42), denominou como "waterfront" a transformação da frente portuária das cidades. Descreveu "waterfront" como a área da cidade adjacente à água e que podia associar-se às intervenções das áreas dos antigos portos, sendo transformadas em áreas urbanas da cidade, convertendo os molhes numa ligação entre a cidade e o mar.

Existem ainda diversas publicações promovidas por entidades públicas e privadas sobre "waterfronts", nomeadamente sobre intervenções urbanísticas como FjordCity em Oslo e Marsella Euroméditerranée. Surgiram ainda estudos comparativos desenvolvidos para a reorganização e reutilização de áreas urbanas portuárias para ilustrar a dinâmica de diversas cidades, como foi o caso do "Projecto Città del'Acqua" em Veneza (1991) coordenado pelo arquitecto Rinio Bruttomesso e o arquitecto Nuno Portas (1998) escreveu sobre "waterfronts" no livro "Cities \& Waterfronts".

Outros estudos comparativos, destacam-se o de Richard Marshal (2001) em "Waterfronts in Post-Industrial Cities" e o estudo de Han Meyer (1999) em "City and Port: urban planning as a cultural venture in London, Barcelona, New York and Rotterdam". Richard Marshal (2001) estudou as transformações das novas frentes de água como espaços de desenvolvimento urbano em cidades como Amesterdão, Génova, Sidney e Vancouver.

\section{OBJECTIVOS: GERAL E ESPECÍFICOS}

O objetivo principal desta investigação é avaliar a função dos portos como âncora de desenvolvimento territorial das pequenas e médias cidades europeias com canais aquáticos, enquanto elementos centrais de organização espacial e funcional urbana. Pretende-se concretizar este objetivo com o caso de estudo: porto e cidade de Aveiro.

Assim, no âmbito desta investigação, são analisados os impactos diretos, indiretos, induzidos e catalíticos dos Portos nas cidades e nas regiões selecionadas na investigação e suas consequências urbanísticas.

O objetivo principal será decomposto em vários objetivos específicos com escalas territoriais diferentes, com a mesma temporalidade, tendo como caso de estudo "porto e cidade de Aveiro", onde serão referenciadas as boas práticas e problemáticas de cinco pequenas e médias cidades portuárias europeias com canais aquáticos. Assim, a investigação visa:

(a) avaliar de forma comparativa se cidades com organizações espaciais e funcionais similares (pequenas e médias cidades portuárias com canais) na Europa assinalam características demográficas, económicas e urbanísticas específicas (efeitos na estruturação do território) através de levantamento de dados estatísticos e cartográficos;

(b) perceber se a evolução urbana suportada pela análise dicotómica entre morfologia e transformações urbanas considera os portos ao longo dos dois últimos séculos como cenários relevantes para a sustentabilidade económico-social das cidades e das regiões nas cidades selecionadas e no caso de estudo; (c) explorar os impactos causados pelos portos no desenvolvimento urbano e territorial, nomeadamente nos seus hinterlands e no caso de estudo "Aveiro" através do método de benchmarking ${ }^{2}$;

2 Benchmarking é um processo de comparação de produtos, serviços e práticas empresariais, e é um importante instrumento de gestão das empresas. O benchmarking é realizado através de pesquisas para comparar as ações de cada empresa. 
(d) identificar comparativamente as boas práticas e os principais problemas referentes ao caso de estudo "Aveiro" e ao conjunto de cidades selecionadas na respetiva investigação.

Para cumprir os objetivos traçados, a investigação pretende estruturar uma matriz de critérios de análise como principal ferramenta de análise de dados quantitativos e qualitativos, segundo um fio condutor que tem como foco principal desta investigação, a análise dos portos como âncora de desenvolvimento territorial.

Para análise e avaliação dos objetivos referenciados, é elaborada uma abordagem metodológica que se estrutura no paradigma qualitativo e quantitativo, no sentido em que o estudo quantitativo envolve a definição clara das variáveis e critérios usando-os para obter resultados quantificáveis. No estudo qualitativo da investigação propõe-se verificar um fenómeno por meio da observação e estudo do mesmo (Kirk e Miller,1986), segundo a metodologia proposta no ponto 4.

\section{ABORDAGEM METODOLÓGICA}

É importante destacar que a investigação se baseia numa base cartográfica com elementos singulares que se modificam com o tempo, pelo que surge a necessidade de acompanhar as dinâmicas e tendências urbanas através da ferramenta principal do arquiteto, "mapa". No passado, presente e futuro, os mapas constituem uma perpetuação da imagem do território, tendo limitações como a escala, a dimensão e a expressão gráfica. No entanto, os sociólogos e os geógrafos têm algumas ferramentas chave como entrevistas e inquéritos, e os arquitetos encontram nos mapas a representação do território e dos planos de intervenção no mesmo. Para isso, a investigação no âmbito da tese em desenvolvimento está direcionada para a elaboração de mapas que permitirão interpretar a realidade territorial e completar os mesmos com uma matriz de critérios e com a descrição referente aos dados estatísticos no âmbito gráfico. Os métodos a utilizar no desenvolvimento da tese são divididos em quatro etapas:

4.1) a primeira etapa tem por objeto a compilação de material gráfico (plantas, fotografias antigas e recentes), de material bibliográfico (documentos históricos e atuais, dados estatísticos) e análise de dados gráficos e descritivos, com um ponto de partida teórico sobre o impacto dos portos nas cidades e regiões e as transformações urbanísticas do território provenientes da presença dos portos, tendo como característica principal as pequenas e médias cidades europeias com a especificidade morfológica da malha urbana, "Os canais aquáticos".

4.2) a segunda etapa consiste na análise do material gráfico (plantas, planos de ordenamento de diversas épocas, ortofotomapas, fotografias antigas e atuais), pelo que esta fase está dividida em várias ações, nomeadamente: a) delimitação física da área e desenvolvimento cronológico do território; b) seleção de informação gráfica e estatística; c) mapeamento de critérios; d) determinação dos elementos a georreferenciar; e) elaboração de cartografia temática com base nos dados estatísticos e gráficos; f) matriz de análise dos resultados dos dados estatísticos, critérios e cartografia.

Para atingir a meta desta investigação, determinou-se trabalhar com duas escalas territoriais distintas: a) escala local: 1:5000 e 1:10000; b) escala regional 1:25000 e 1:1.50.000. A investigação principal realiza-se entre a escala 1: 5000 e 1:10000, por forma que se assegure o detalhe do espaço urbano.

4.3) a terceira etapa consiste na elaboração de um estudo comparativo do território referente às pequenas e médias cidades portuárias europeias selecionadas e elaboração de uma matriz com as boas práticas e os principais problemas dessas cidades (escala local) e dos seus hinterlands (escala regional).

4.4) a ultima etapa resume-se à interpretação escrita das realidades territoriais expressadas na matriz de critérios e na cartografia das cidades selecionadas, relacionando as conclusões provenientes da observação com as tendências territoriais, fazendo o estudo sobre os impactos do Porto na cidade e na região de Aveiro. Estes impactos, são estudados nos aspetos socioeconómicos, tecnológicos, ambientais, acessibilidade, segurança e urbanísticos. Para análise dos respetivos impactos é necessária uma classificação funcional das atividades no interior do porto e das atividades desenvolvidas no território envolvente ao porto. Será feita a avaliação de ambos os territórios (porto, cidade e região) no âmbito dos impactos referidos anteriormente. Será feita uma matriz de análise com a avaliação dos critérios e indicadores usados na análise, tendo como objetivo a classificação dos efeitos na estrutura territorial. Finalmente serão analisadas as consequências na estruturação urbanística e relacionar as mesmas com a evolução do transporte marítimo e com a dinâmica socioeconómica do território "porto-cidade-região".

Desta forma, a metodologia a adotar é estruturada sobre os diversos métodos enunciados nas quatro etapas referidas anteriormente, adotando critérios para análise dos portos enquanto âncora de desenvolvimento da estrutura urbanística, nomeadamente do seu hinterland consoante as funções que desempenham.

A presente investigação integra cinco pequenas e médias cidades portuárias europeias com canais aquáticos, nomeadamente Porto de Antuérpia e cidade de Mechelen, Porto e cidade de Bruges, Porto e cidade de Gent, Porto e cidade de Veneza e Porto e cidade de Huelva, tendo como estudo de caso a cidade e o porto de Aveiro (Quadros 1 e 2). 


\section{CIDADES E PORTOS SELECCIONADOS}

\begin{tabular}{|c|c|c|c|}
\hline $\begin{array}{l}\text { Cidades e Portos } \\
\text { seleccionados }\end{array}$ & $\begin{array}{c}\text { Cidade } \\
\text { (n habitantes) }\end{array}$ & $\begin{array}{c}\text { Concello } \\
\text { (n habitantes) }\end{array}$ & $\begin{array}{c}\text { Regiáo } \\
\text { (n habitantes) }\end{array}$ \\
\hline Aveiro & 32187 & 76909 & 364385 \\
\hline Gent & 253266 & 544959 & 1477376 \\
\hline Antuérpia (Porto) & 513570 & 1027342 & 1824136 \\
\hline Bruges & 117886 & 280153 & 1178996 \\
\hline Huelva & 146318 & 146318 & 520017 \\
\hline Veneza & 103306 & 347480 & 4915123 \\
\hline Mechelen & 83975 & 335418 & 1825136 \\
\hline Tot: & 1250508 & 2758579 & 12105169 \\
\hline
\end{tabular}

Quadro 1: Dados demográficos das cidades e portos em estudo

(www.citypopulation.de/php/portugal-admin.php?adm2id
5000000

3750000

2500000

1250000

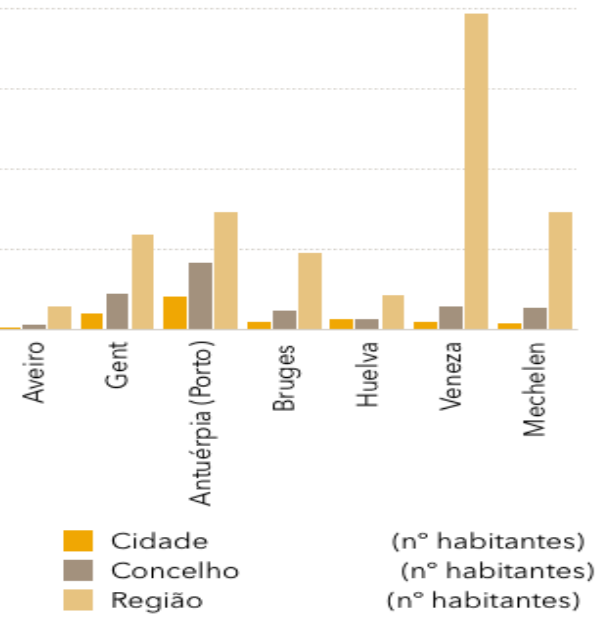

Quadro 2: Gráfico da demografia das cidades, concelhos e regiões das cidades em estudo $\left(\right.$ IECA $^{3}$ e INE $\left.^{4}\right)$

\section{CONTEXTUALIZAÇÃO DO CASO DE ESTUDO}

O objeto de estudo selecionado trata-se do porto e da cidade de Aveiro, sendo esta a única cidade em Portugal com canais aquáticos que conectam com parte da área urbana. Aveiro localiza-se estrategicamente no centrolitoral do território português, no litoral da Península Ibérica e na área territorial sul da Europa (Figura 12). Portugal localiza-se no corredor oceânico da economia europeia, no que se refere ao transporte e mobilidade sustentada pelo mar, o que lhe confere um aspeto singular no território europeu.

A cidade de Aveiro tem uma superfície de 45,32 km2 (Censos 2012). O Concelho tem uma área total de 197,5 km2 (CAOP 5 , 2013) e integra uma população residente de 78450 habitantes (Censos, 2011).

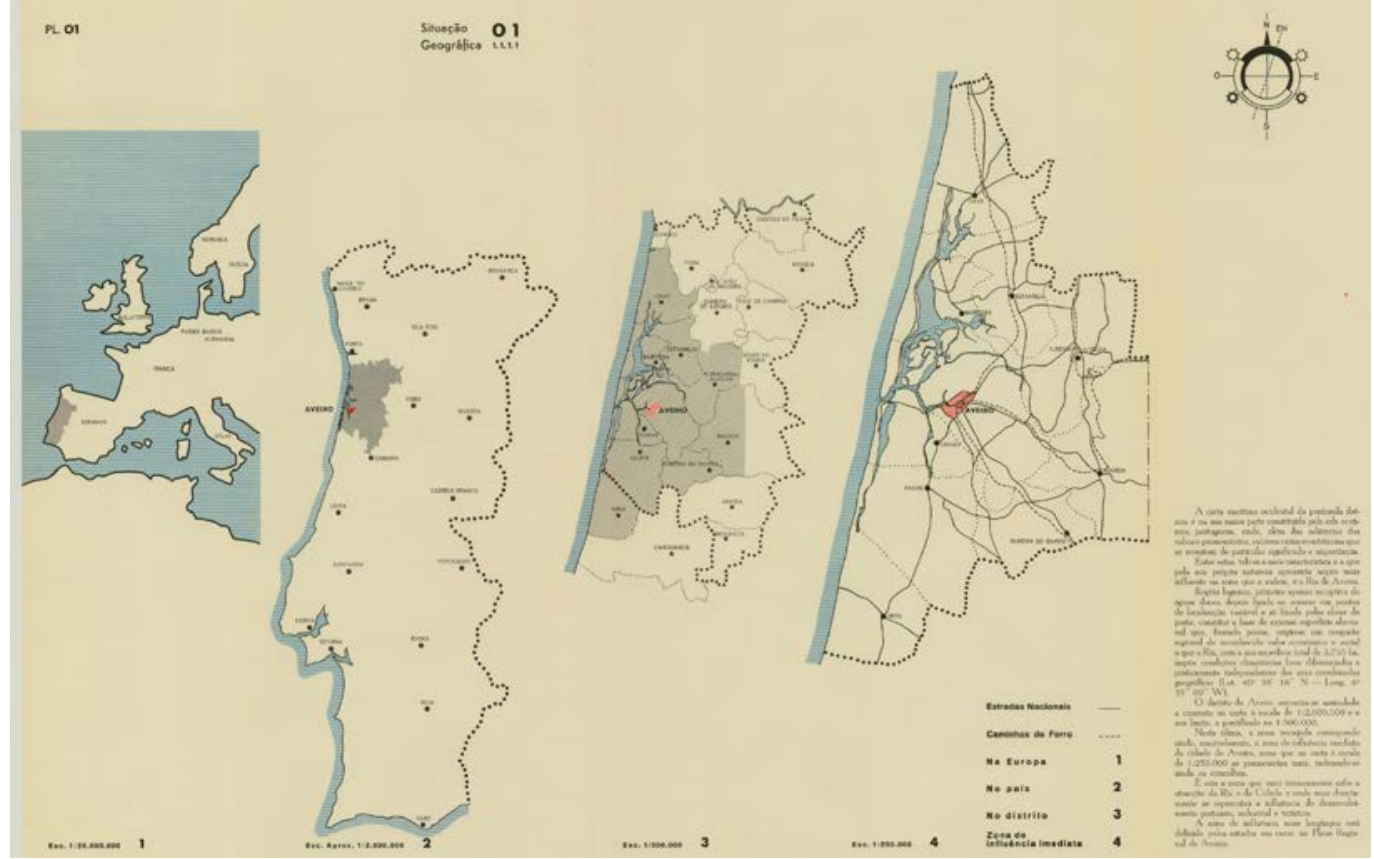

Figura 14: Localização de Aveiro (Planta 01 do Plano de Urbanização da Cidade de Aveiro de 1964) (Auzelle,1964) 
Aveiro é identificada nacionalmente e internacionalmente por uma identidade caracterizada pela paisagem natural (Ria e salinas) e pela paisagem cultural (canais aquáticos e património cultural). A Cidade Baixa, desenvolve-se ao longo dos vários canais aquáticos, "limites aquáticos" (Kevin Lynch,1989) que definem e dividem duas áreas que funcionam como "referências laterais". Os canais aquáticos e a avenida Dr. Lourenço Peixinho, constituem os eixos base de mobilidade e de transporte que apoiam o modelo de centralidade da área urbana da cidade de Aveiro (Figura 15).

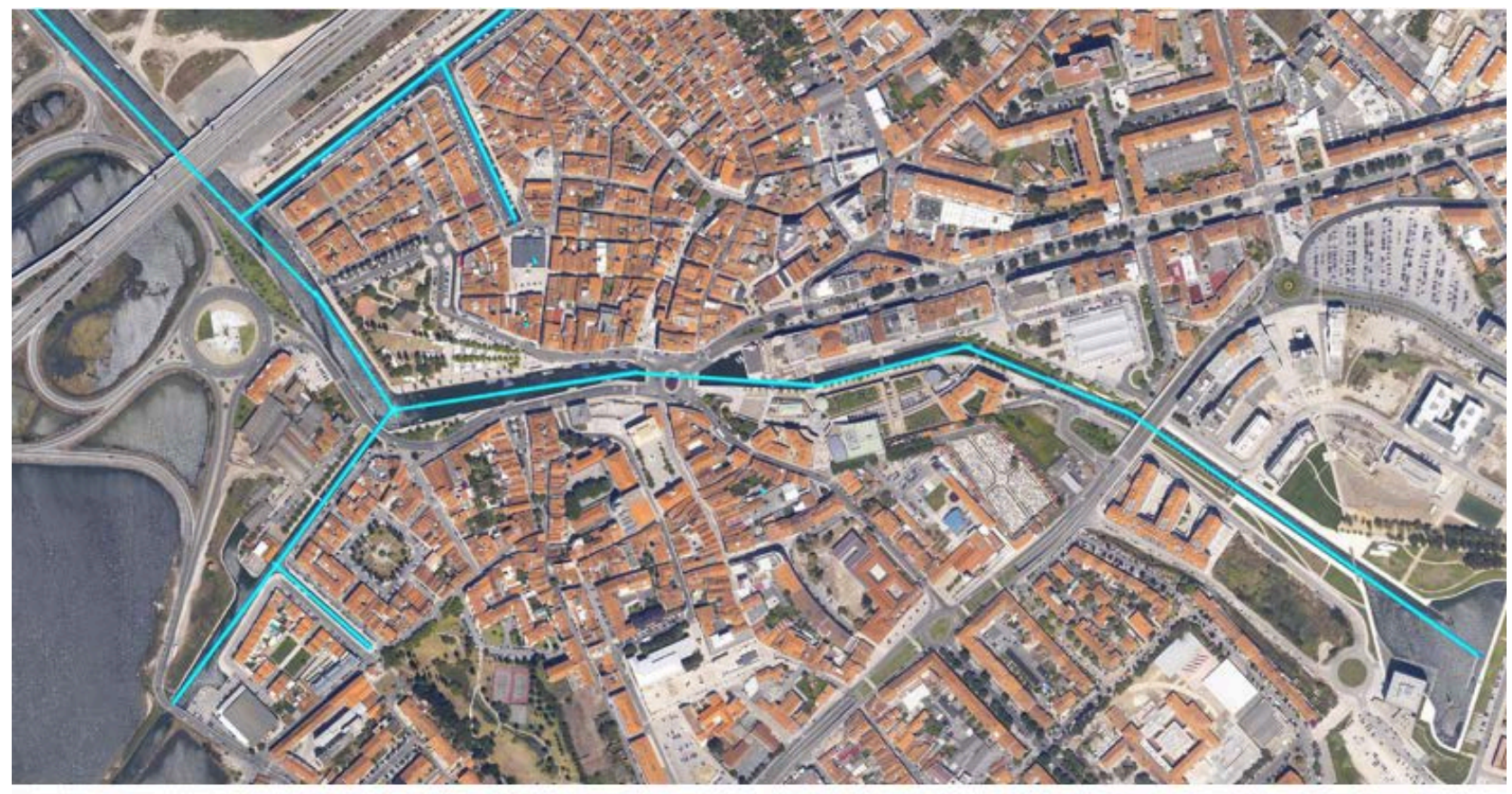

\section{Canais aquáticos de Aveiro}

Figura 15: Ortofotomapa da cidade de Aveiro com a rede dos canais aquáticos Elaboração própria sobre cartografia CMA, 2017

No contexto europeu, as cidades waterfront têm características morfológicas comuns em termos de configuração física, integrando malhas urbanas mistas entre o orgânico e reticulado. A compreensão da estratégia de ocupação territorial é chave para o entendimento das cidades waterfront que cumprem com uma relação a uma rede de cidades, compactas, homogéneas, religiosas, militares e marítimas ou fluviais. No caso de Aveiro, Inês Amorim (1996:60) refere que a cidade teve origem militar, religiosa e marítima, nomeadamente na existência de muralha no século XV, na construção de diversas igrejas no interior e exterior da muralha, na construção da barra do porto de Aveiro em 1808.

No âmbito atual, encontra-se alguma ambiguidade quando se observam os conceitos urbanos e territoriais de Aveiro, dado que a investigação sobre o "porto de Aveiro", a "cidade de Aveiro", a "região de Aveiro" e "região Centro" têm escalas territoriais distintas com evoluções morfológicas diferentes. Assim, o caso de estudo "porto e a cidade de Aveiro" está integrado na Região de Aveiro (NUT III), que por sua vez se integra na Região Centro (NUT II) (Figuras 16 e 17), pelo que a investigação sobre o "Porto na cidade", a "cidade no Porto" e o "Porto e a cidade" são temas em estudo nesta investigação, mas de forma distinta, dado que os impactos causados uns sobre os outros alteram a estrutura urbanística que por sua vez, têm origem no âmbito socioeconómico, ambiental, tráfego, segurança e morfológico. 


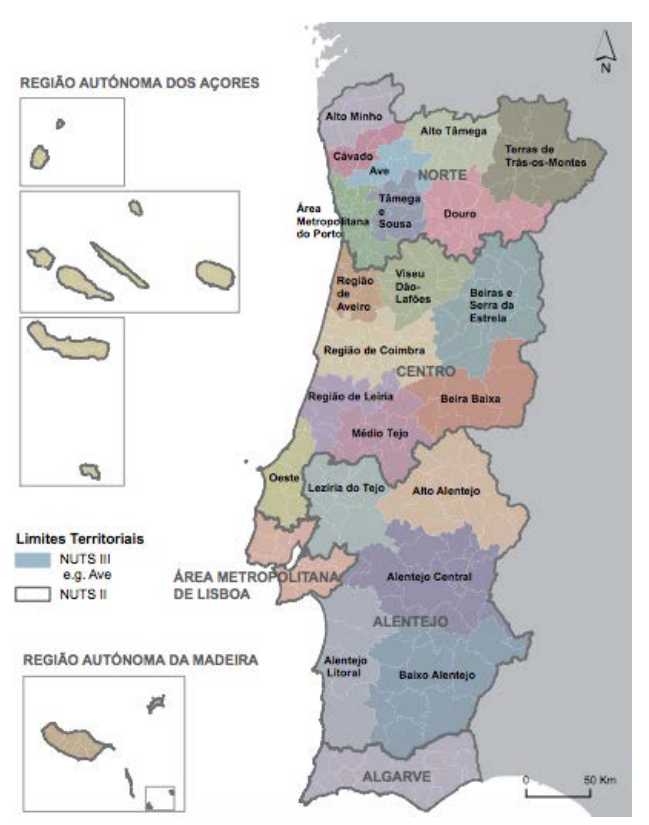

Figura 16: Mapa das NUTS II e III (INE,2015)

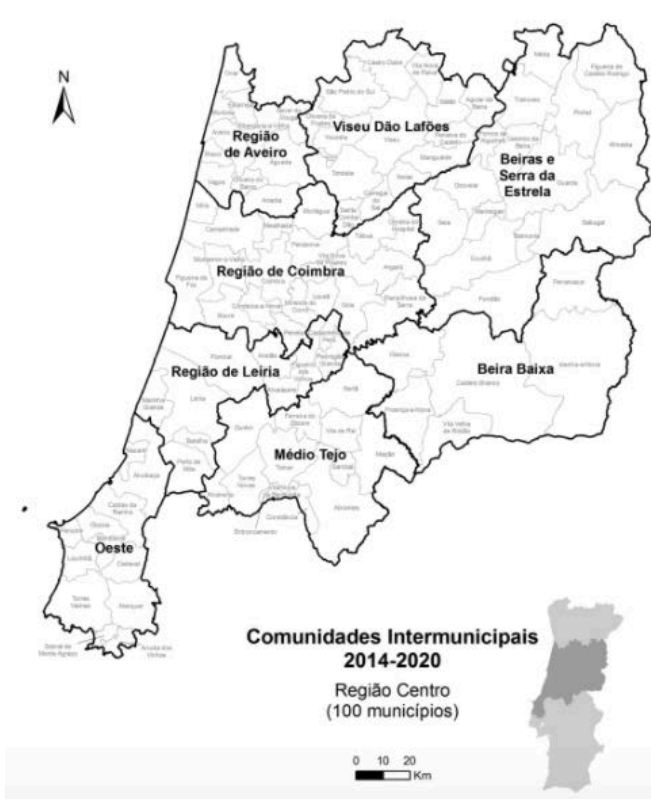

Figura 17: Mapa da Região Centro e NUTS III (CCRC, 2016)

Aveiro, dispõe de vantagens competitivas muito próprias, nomeadamente a sua proximidade ao mar, a existência de um porto comercial, o caminho-de-ferro, as diversas ligações viárias (A25, A1, A17, EN109, EN235), a universidade, o turismo e a industria. A região centro de Portugal surge como hinterland natural do porto de Aveiro (Figura 18) e tem uma grande influência sobre a atividade do porto e também é a área mais influenciada pela infraestrutura portuária. Esta região situa-se entre as duas maiores áreas metropolitanas portuguesas, nomeadamente Porto e Lisboa, com uma ligação viária de Aveiro a Espanha pela A25 e pela ligação ferroviaria através da linha do Norte (que liga o Porto a Lisboa). A ligação entre o porto de Aveiro e a Europa é feita através da articulação do transporte multimodal marítimo e terrestre, através da ligação do Porto de Aveiro à linha do Norte (Portugal) e à linha da Beira Alta (Portugal-Espanha). Existe alguma carência na intermodalidade de transportes, essencialmente no aspeto aéreo, dado que a região não tem aeroporto regional. "Neste sentido, a inexistência de um aeroporto regional com dinâmica em transporte de bens e pessoas, contribui para o reduzido crescimento da intermodalidade dos transportes que poderia proporcionar o desenvolvimento equilibrado de uma região, com custos repartidos pelos vários clusters industriais que se desenvolvem na circunscrição das várias empresas de transportes, como apoio às mesmas" (Matias \& Salvador \& Rosa Pires, 2015:2). 


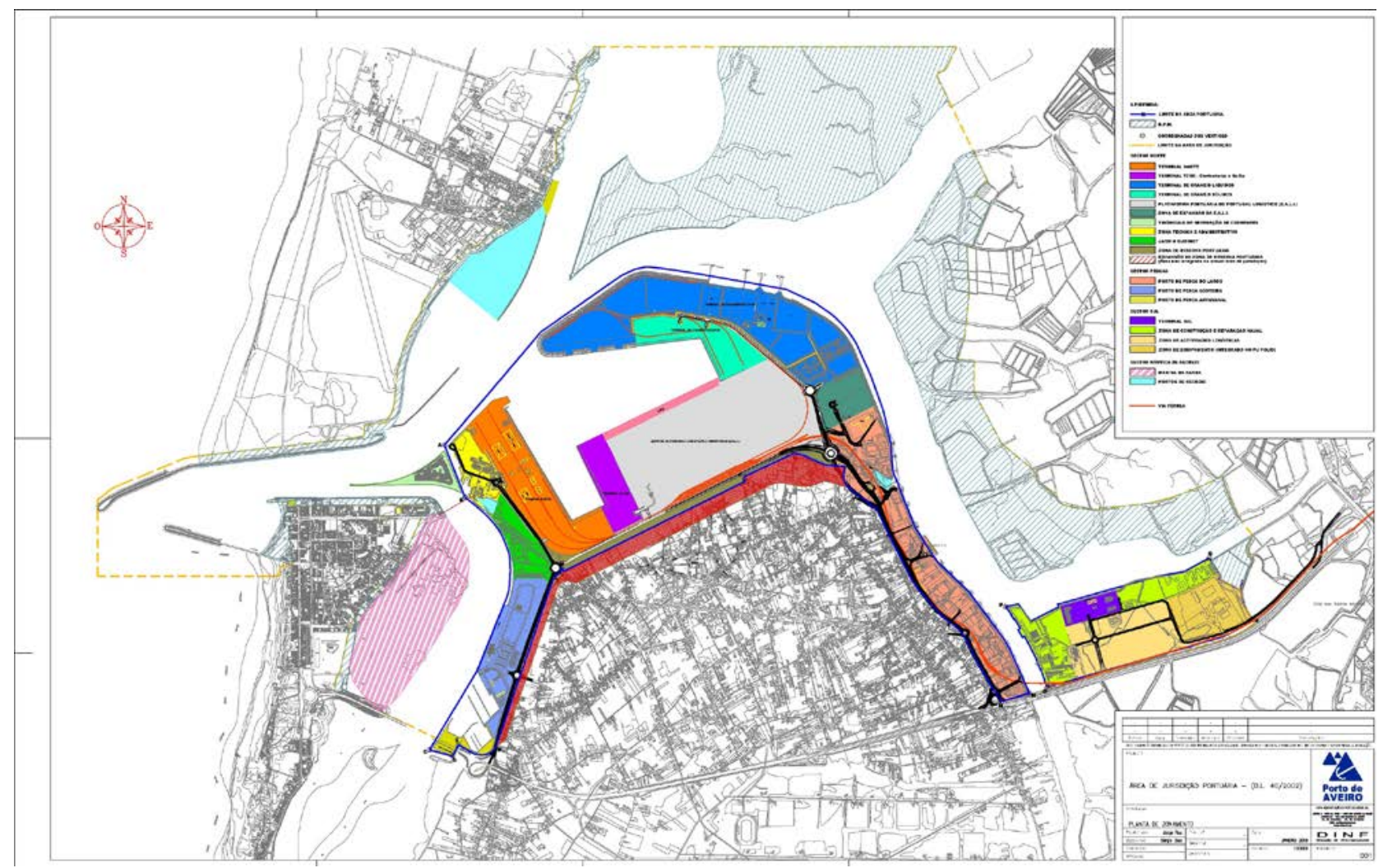

Figura 18: Planta do Porto de Aveiro e suas funcionalidades

(APA, 2008)

O porto de Aveiro (Figura 19) é considerado a maior infraestrutura de movimentos de carga geral no centro de Portugal, sendo possível a ligação a múltiplos destinos e mercados internacionais. Com um tráfego anual cerca de 4,5 milhões de toneladas de mercadorias, o porto de Aveiro é multifuncional e desempenha um papel primordial no apoio à atividade económica e à capacidade de exportação de muitas indústrias portuguesas, pelo que se assume como um nó logístico do centro da Península Ibérica. A plataforma multimodal de Cacia é acessível através de transporte terrestre, nomeadamente através de camiões e de comboios, com uma distância de aproximadamente de $8,8 \mathrm{Km}$ até ao porto de Aveiro. Existe ainda uma parceria entre os operadores ferroviários CP Portugal e RENFE Espanha, nomeadamente o serviço Iberian Link, onde é feita a conexão semanal através do transporte ferroviário que faz a interligação entre o porto de Aveiro e os centros logísticos espanhóis. Alguns dos centros logísticos onde é feita a intermodalidade de transportes, destacamse Salamanca (Zaldesa e Cetramesa) e Madrid (CTM). 

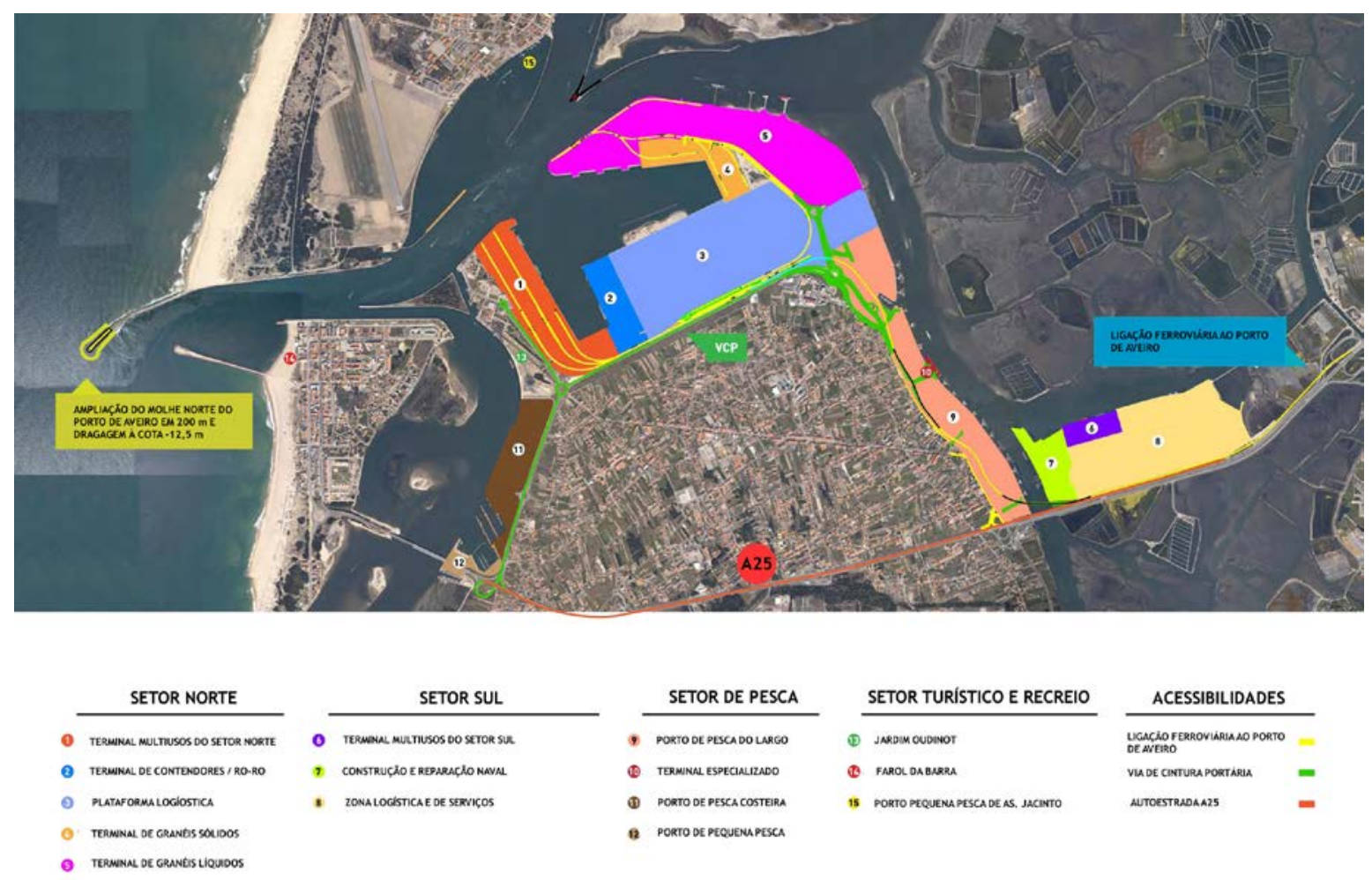

Figura 19: Ortofotomapa do Porto de Aveiro (APA, 2015)

O porto de Aveiro surge assim como centro de ligação intermodal entre o transporte terrestre e marítimo das mercadorias provenientes das diversas regiões integradas na Região Centro: região de Aveiro (a), região de Coimbra (b), Viseu e Dão-Lafões (c), Região de Leiria (d), Beiras e Serra da Estrela (e), Oeste (f), Beira Baixa (g), Médio Tejo (h):

a) assim, a região de Aveiro onde se localiza o porto e a cidade de Aveiro, integra diversas industrias que utilizam o porto de Aveiro, nomeadamente a zona norte de Aveiro onde se concentra a industria da cortiça, metalomecânica, componentes automóveis, industria química; a zona de Ovar e Estarreja integra industrias como a Philips, Nestlé, Yazaki Saltano, Toyota-Salvador Caetano, Grupo Bosch e Dow Portugal; o concelho de Aveiro e de Ilhavo, integra um índice elevado de industria cerâmica, de maquinaria (Vulcano), de componentes automóveis (Renault), de construção naval (NavalRia), de refinaria (Prio) e de industria de processamento de peixe (Friopesca), além da Universidade de Aveiro se tratar de um núcleo de conhecimento que contribui para o desenvolvimento das empresas da área de especialização em telecomunicações e telemática, nomeadamente a PT Inovação e a Sapo; ainda na região de Aveiro, integra-se o concelho de Anadia e Mealhada, onde se concentram industrias metalomecânicas (Mahle) e de cerâmica (Sanitana). "Estas áreas aliadas às infraestruturas de transporte existentes na região tornam a Região Centro, nomeadamente a Região de Aveiro, uma área atractiva para o tecido empresarial, o que contribui para o desenvolvimento económico e social desta área territorial" (Matias, Salvador, Rosa Pires, 2015:3).

b) a Região de Coimbra integrada na Região Centro contempla grande concentração industrial no sector da industria do cimento (Cimpor) e do papel (Portucel Soporcel e Altri SGPS), utilizadoras do porto de Aveiro.

c) Viseu e Dão-Lafões integram industria transformadora de madeira (Sonae Industria), energia eólica (Martifer) e montagem automóvel (Citroen), que utilizam o transporte marítimo proveniente do porto de Aveiro. d) a Região de Leiria, onde predomina a industria de moldes e de vitrocerâmica, também utilizam o porto de Aveiro como acesso ao transporte marítimo.

e) as Beiras e Serra da Estrela surgem como núcleo industrial dessa região, com especialização na área da industria agroalimentar, têxteis e peles, também utilizadoras do porto de Aveiro.

f) o Oeste, integra industrias agroalimentares, cerâmicas e de vidro que utilizam o transporte marítimo do porto de Aveiro.

g) a Beira Baixa é caracterizada por três elementos geográficos (grande dimensão territorial, região interior e proximidade da fronteira com Espanha, nomeadamente a Província de Cáceres) que são factores importantes para a compreensão das dinâmicas socioeconómicas. O perfil empresarial da Beira Baixa apresenta uma estrutura produtiva dedicada a indústrias dependentes dos recursos naturais, nomeadamente a produção de cana de açúcar, de tabaco e de pasta de papel. 
h) o setor terciário (comércio por grosso/a retalho e alojamento e restauração) predomina no Médio Tejo, zona que não utiliza os serviços do porto de Aveiro (Figura 20).

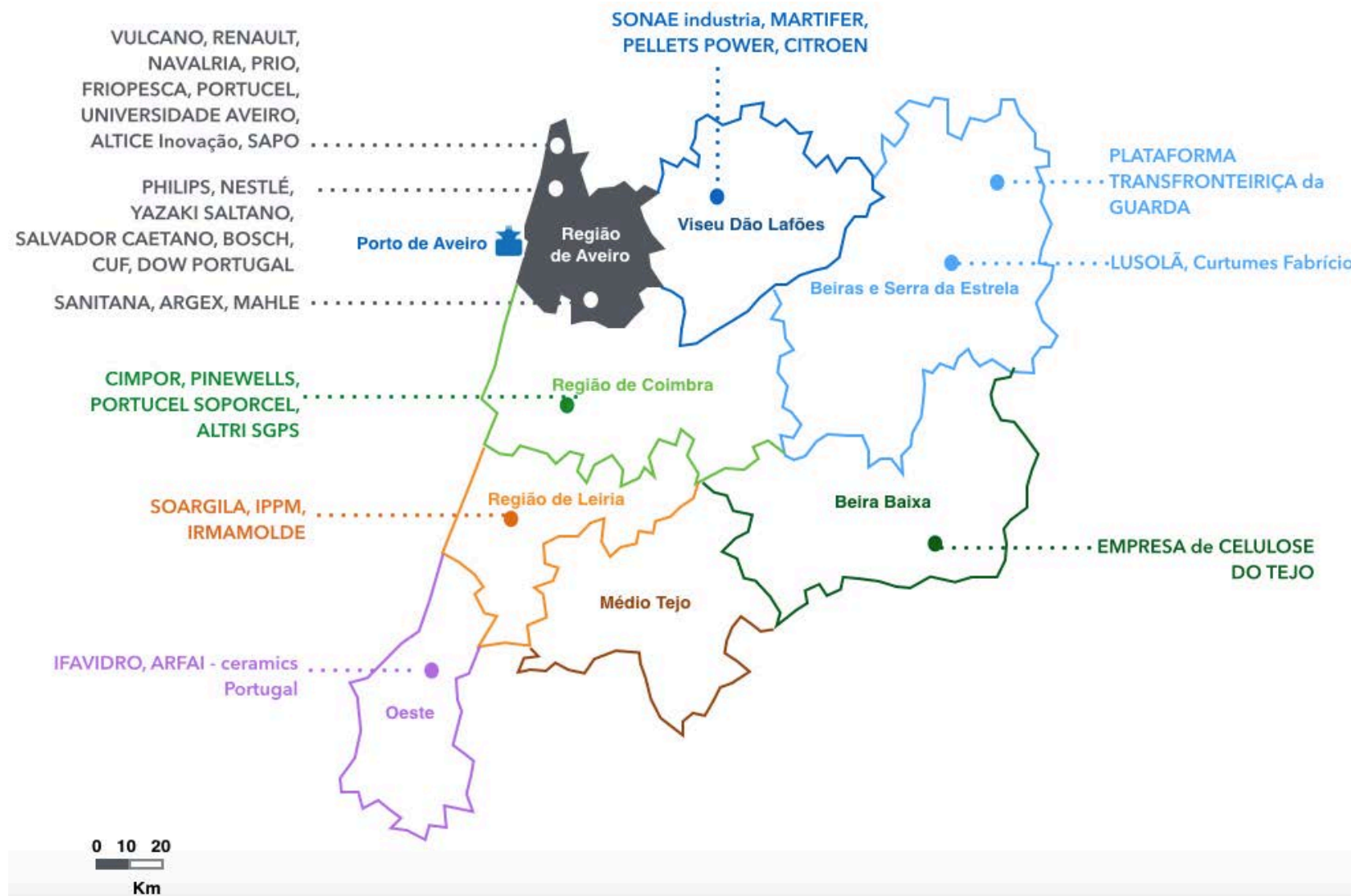

Figura 20: Cidade de Aveiro, Região de Aveiro e Região Centro

(Elaboração própria a partir de dados CCRC e levantamento in loco, 2018)

O hinterland do porto de Aveiro além de integrar a região Centro, tem como objetivo expandir-se para a região de Castela e León (Espanha), devido à sua proximidade terrestre. Esta região espanhola é marcada pela industria agroalimentar (vitivinícola, cereais e óleo de girassol) e automóvel (Renault) (Figura 21). 


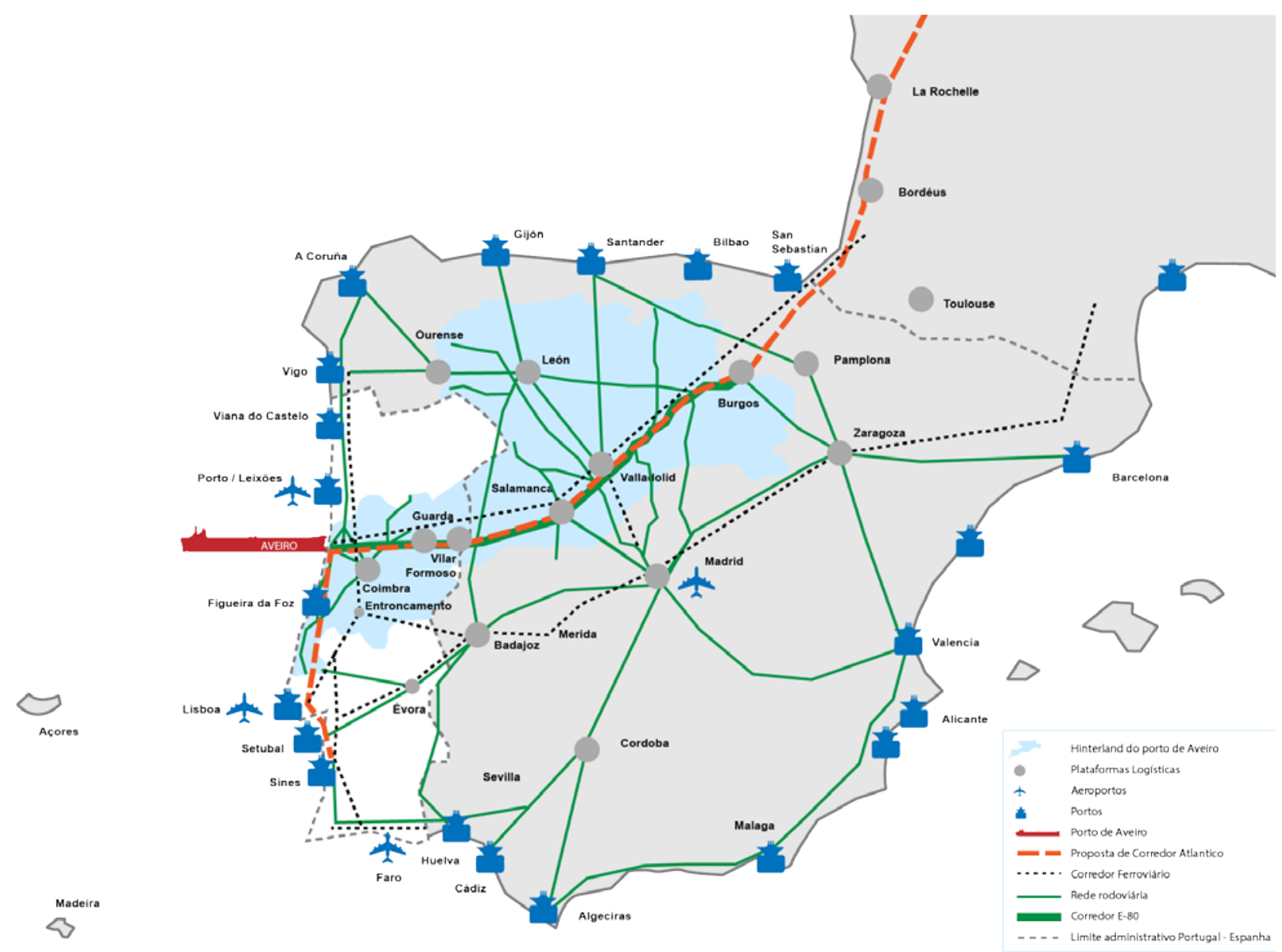

Figura 21: Hinterland do Porto de Aveiro

(Elaboração própria segundo dados da APA, 2017)

\section{CONCLUSÃO}

A relação das cidades portuárias com os seus portos tem vindo a alterar-se ao longo dos tempos, gerando múltiplos espaços no território e no tempo. Um dos momentos importantes do desenvolvimento portuário, tem sido marcado por diversas transformações tecnológicas na época industrial que modificou a geografia física e a relação destas cidades com os seus portos provocando em muitas destas cidades o esquecimento da sua condição portuária, uma função que algumas cidades esqueceram ao longo da história; estas cidades portuárias eram uma âncora que moviam o mundo no passado. Não existe um modelo único da cidade portuária, dado que esta contem uma dinâmica que implica várias dimensões no âmbito geográfico, histórico, socioeconómico, tecnológico e ambiental.

Assim, Aveiro integra-se nas cidades que se esqueceram da sua identidade portuária, que teve origem no século XV através das embarcações que chegavam via marítima à parte baixa da cidade de Aveiro para descarregar café, açúcar e outros produtos e carregar moliço. Desde o século XV o mar era um meio condutor de desenvolvimento da cidade e da região de Aveiro. Atualmente, a cidade de Aveiro não tem qualquer relação com o porto de Aveiro, enquanto a região de Aveiro e Centro têm uma interdependência forte em relação ao porto de Aveiro. Assim, o porto de Aveiro tem grandes influências na escala metropolitana (região de Aveiro e Centro) enquanto na escala urbana a influência é muito reduzida ou praticamente nula. Desta forma, a investigação centra-se em duas escalas distintas, nomeadamente a escala metropolitana nos impactos porto - região de Aveiro - região Centro enquanto os impactos e transformações urbanísticas são estudados na escala urbana, porto - cidade de Aveiro. Será elaborada uma estratégia urbanística para a relação porto cidade de Aveiro por forma que a relação entre estes dois territórios crie uma simbiose e uma dependência entre os mesmos e contribuam para um grande desenvolvimento socioeconómico da área urbana circunscrita à cidade e ao porto. 


\section{BIBLIOGRAFIA}

AMORIM, Inês (1996). Aveiro e a sua Provedoria no século XVIII (1690-1814), Faculdade de Letras do Porto, Coimbra: CCRC- Comissão de Coordenação da Região Centro.

AUZELLE, Robert (1964). Plano de Urbanização da Cidade de Aveiro. Aveiro: CMA.

BORJA, Jordi \& CASTELLS, Manuel (1998). Local y global. La gestíon de las ciudades en la era de la informacíon. Madrid: Taurus.

BIRD, James (1963). The Major Seaports of the United Kingdom in BIRD, J. H. Chapter 1 - Anyport After Three Eras of Development. (21-36). London: Hutchinson University Library.

BRAUDEL, Fernand (1979). Civilisation matérielle, économie et capitalisme, XVe-XVIII siècle. Volume 3. Paris: Armand Colin.

BUSQUETS, Joan (2011). Desarollo urbano y crecimiento portuário. O viceversa? Venezia: RETE.

CASTELLS, Manuel (1999). A sociedade em rede. S. Paulo: Paz e Terra.

CHALINE, Claude (1988). La conversion des espaces fluvio-portuaires dans les grandes metrópoles, n.544.

(695-715). Paris: Annales de Géographie.

CHALINE, Claude \& MALTA, Rodrigues (1994). Ces ports qui créèrent des villes. Paris: L'Harmattan.

CHARLIER, J. \& MALÉZIEUX, J. (1997). Les stratégies alternatives de redéveloppement portuaire em Europe du nord-ouest in BAUDOUIN, T. \& COLLIN M. \& PRELORENZO, C., Urbanité des cités portuaires, L'Harmattan. Paris: Collection Maritimes.

COCCO, Giuseppe \& SILVA, Gerardo (1999). Cidades e portos: os espaços da globalização. Rio de Janeiro: DP\&A.

DUCRET, César (2011). Análisis multidisciplinar de la ciudad portuária, in ALEMANY, Joan \& BRUTTOMESSO, Rinio, La ciudad portuária del siglo XXI. Nuevos desafios em la relación Puerto-Ciudad. Venezia: RETE.

FIGUEIRA de SOUSA, João (2011). Reflections on Port-City relations: interpretative models and new approaches. Venezia: RETE.

HARVEY, David (1989). Condição pós-modern. S. Paulo: Loyola.

HAYUTH, Yehuda (1982). The port-urban interface: an area in transition, $n^{\circ} 3$ (219-224). Londres: Area.

HENRY, Magali (2006). Villes portuaires en mutation - Les nouvelles relations ville-port à Marseille dans le cadre du programme de renouvellement urbain Euroméditerranée. Mémoire de Master, Université de Lausanne. Lausanne: Institut de Géographie.

HOYLE, Brian (1989). The port-city interface: trends, problems, and examples, Geoforum, vol. 20, no 4, pp. 429-425. Quoted in César Ducruet, 2007, A metageogrpahy of port-city relationships, Ports, cities and global supply chains. London: Aldershot, Ashgate.

KIRK, Jerome \& MILLER, Marc (1986). Reliability and Validity in Qualitative Research. London: Sage Publications.

KONDRATIEV, Nikolai (1984). The long wave cycle. New York: Richardson \& Snyder.

LAVAUD-LETILLEUL, Valérie (2007). Ports: la tentation du tout-réseau face aux pesanteurs du territoire? XLIII ème colloque de l'Association de Science Régionale de Langue Française (ASRDLF). GrenobleChambéry.

LEMAIRE, Olivier (2007). Plan the city with the port, guide of good practices. Le Havre: AIVP.

LIGTERINGEN H. (2010). What's new? The Port of the future. Delft: TU-Delft.

LYNCH, Kevin (1989). A imagem da cidade. Lisboa: Edições 70.

MARSHALL, Richard, (2001). Waterfronts in Post Industrial Cities. New York: Spon Press.

MATIAS, Lidia; SALVADOR, Regina; ROSA PIRES, Artur (2015). Portugal: Porto de Aveiro e Região Centro como âncora do desenvolvimento territorial, PORTUS, $n^{\circ} 29$ (2-3). Venezia: RETE.

MEYER, Han (1999). City and Port: Urban Planning as a Cultural Venture in London, Barcelona, New York and Rotterdam: changing relations between public urban space and large-scale infrastructure. Roterdão: International Books.

MEYER, Han (2011). The Port-City in the era of Globalization: the second transformation. RETE: Venezia.

MONIÉ, Frédéric (2011). Globalização, modernização do sistema portuário e relações cidade/porto no Brasil in Silveira, M R. (org.), Geografia dos transportes, circulação e logística no brasil. (229-330). S. Paulo: Outras Expressões.

MUSSO, Enrico \& GHIARA, Hilda (2011). Transformando el programa económico de ciudades portuárias. Venezia: RETE.

PORTAS, Nuno (1998). Cidades e frentes de agua, Cities and waterfronts. Porto: Edições FAUP.

SEASSARO, Loredana (1999). O sistema portuário italiano: privatização, operadores transnacionais e recomposição da relação porto-cidade in COCCO, G.; SILVA, G. (Orgs.). Cidades e portos: os espaços da globalização. Rio de Janeiro: DP\&A. 
SHUBERT, Dirk (2011). A shift from ships to chips. Waterfront transformation in european seaports. Venezia: RETE.

VERHOEVEN, Patrick \& BACKX, N. (2010). Code of practice on societal integration of ports. Brussels: ESPO. VIGARIÉ, André (1979). Ports de commerce et vie littorale. Paris: Hachette.

WANG, J. J. \& OLIVIER, Deslondes (2003). La gouvernance des ports et la relation ville-port en Chine, Les Cahiers Scientifiques du Transport, $\mathrm{n}^{\circ}$ 44, (25-54). Lyon.

\section{Fontes da internet:}

http://www.citypopulation.de/php/portugal-admin.php?adm2id

http://sig.riadeaveiro.pt/web/ 